\title{
Construction and Practice of Medical Imaging Simulation Laboratory
}

\author{
Ronghua Ling ${ }^{1, a, *}$, Hong Liü,b, Chengcheng Fan ${ }^{2, c}$ and Zhexu Li ${ }^{1, d}$
}

${ }^{1}$ School of Medical Imaging, Shanghai University of Medicine and Health Sciences, Shanghai, China

${ }^{2}$ School of Medical Instrument, Shanghai University of Medicine and Health Sciences, Shanghai, China

alingrh@sumhs.edu.cn, bliuh@sumhs.edu.cn, cfancc@sumhs.edu.cn, dlizx@sumhs.edu.cn

${ }^{*}$ Corresponding author

\begin{abstract}
Keywords: Applied Undergraduate, Practical Teaching, Laboratory Construction, Medical Imaging Technology Major.
\end{abstract}

\begin{abstract}
Laboratory construction is very important for the teaching of applied undergraduate professional, is also the essential condition of scientific research work. As a newly established undergraduate university, how to construct teaching laboratory and research is facing a new professional problem. For this, set up medical imaging simulation laboratory, give full play to its function in teaching, scientific research and technology service, improved the medical imaging technology professional students practice teaching effect, raised in the foundation of scientific research in medical image data modeling and simulation, to promote the subject construction.
\end{abstract}

\section{Introduction}

Through combining the quality of education with the application skill education, application-oriented undergraduates can meet the demand of high-level application-oriented talents in Chinese economic transformation period. As a newly established undergraduate university, Shanghai University of Medicine and Health Sciences, based on the cultivation of application-oriented, featured and internationalized talents, is oriented by social needs and ability cultivation, strengthens the cultivation of practical skills, and promotes the cultivation of students' application ability and innovative spirit.

Medical imaging technology is one of the undergraduate majors established by School of Medical Imaging. This major is oriented by the application of medical imaging technology in clinical practice, and cultivates high-level applied talents of medical imaging technology "Medicine plus Engineering". In the professional construction of medical imaging technology, the construction of medical image simulation laboratory is a key link, which is an important place to complete practical teaching, skill competition, subject research, scientific and technological development and training innovative talents[1].

Under this background, School of Medical Imaging set up medical imaging simulation laboratory, on the basis of the hardware and software construction, expand the function of the laboratory, for medical image technology major students in the aspect of image data modeling and simulation of teaching and scientific research base[2], to develop with the engineering practice ability and innovation ability of science and technology of medical imaging technology professionals provide the safeguard.

\section{Construction of medical imaging simulation laboratory}

\subsection{Infrastructure construction}

The medical image simulation laboratory of School of Medical Imaging, with a total area of 120 square meters. The laboratory is equipped with 80 sets of desktop computers, and the model is DELL OptiPlex3050 Micro: CPU main frequency $2.93 \mathrm{Ghz}$, dual-core, secondary cache $3 \mathrm{M}$, front-end bus 
frequency $1066 \mathrm{MHz}$, memory type DDR3, capacity $8 \mathrm{~GB}$, hard disk capacity $1 \mathrm{~TB}$, network co-transmission and hard disk protection card installation, SATA7200rpm/21.5 inch wide screen LCD. In order to ensure a good computer operating environment and teaching environment in the simulation lab, the computer room is also equipped with network switches, teaching multimedia, air conditioning and other equipments, with a total of more than 90 sets of equipments. The overview of the medical image simulation laboratory is shown in Fig. 1.

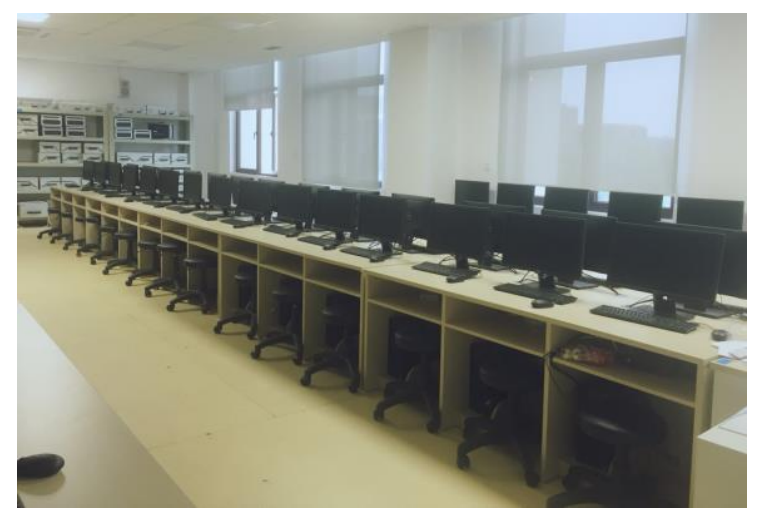

Fig. 1. The overview of medical imaging simulation laboratory.

\subsection{Software construction}

\subsubsection{Medical imaging electronics integrated simulation software series}

This series of software includes: Proteus Professional, ImageCraft Development Tools, Atmel AVR Tools. The Proteus Professional is a complete software solution for circuit simulation and PCB design. It comprises several modules for schematic capture, firmware IDE and PCB layout that appear as tabs inside a single, integrated application[3]. ImageCraft Development Tools and Atmel AVR Tools Atmel AVR Tools is used to compile and download the practical operation of AVR series MCU(Micro Controller Unit).

The medical imaging electronics integrated simulation software series is a huge teaching resource, which can be used in the teaching and practice of analog and digital circuits, teaching and practice of MCU and embedded system software, comprehensive practice of microcontroller system, innovation experiment and graduation design, project design and product development.

\subsubsection{National Instruments software series}

National Instruments is the world's leading business software for VI(Virtual Instruments), which is widely used in the industry. The software group includes: NI MAX, NI LabVIEW, emu8086, ISIS Professional, LabWindows/CVI and Measurement Studio. The main calculation software is NI MAX and NI LabVIEW, and the rest are all supporting pre- and post-processing software. All the above components can be integrated in the National Instruments platform, providing users with a new application experience and virtual instrument simulation environment[4].

The software has a wide range of intersections with the discipline of School of Medical Imaging, among which it has practical virtual simulation means in the field of CT, X-ray machine, MRI and other large imaging equipment.

\subsubsection{MATLAB/SIMULINK calculation and simulation software}

MATLAB is an advanced technology computing language and interactive environment for algorithm development, data visualization, data analysis and numerical calculation[5]. SIMULINK is mainly used for multi-domain simulation and model-based design tools of dynamic system and embedded system.

For various imaging processing and video processing systems, interactive graphics environment is provided, which can be customized module library to design, simulate, execute and test. The software can be integrated with a variety of computer languages, and use the visual interface to build system models, mainly for the simulation of medical imaging processing characteristics.

2.2.4 DR virtual practice teaching system 
DR virtual practice teaching system based on computer simulation technology as the core, for the purpose of study, using a variety of medical image data, using the virtual reality technology, virtual teaching platform is built in computer networking. By establishing virtual DR scenario, constructing the network environment of teaching and learning, so that the students in the virtual network of teaching and learning environment, of course, virtual DR machine organization, interaction, DR debugging installation, operation interaction, knowledge test, and so on, to achieve the purpose of learning and training, optimize the teaching process, improve the quality of teaching[6].

DR virtual practice teaching compared with traditional teaching, autonomy, participatory, interactive, simulation, security, and repetitive incomparable advantages, which not only overcomes the practice DR equipment, training time and space constraints, make up for the deficiency of the teaching conditions, at the same time can help teachers more effectively explain the key points of operation, technical difficulties, and matters needing attention and the ways of error, convenient for students to learn while operating, rich perceptual knowledge, deepen the understanding of the teaching content, is conducive to the cultivation of the students' ability to learn and practice innovation can.. A DR virtual practice teaching system is shown in Fig. 2.

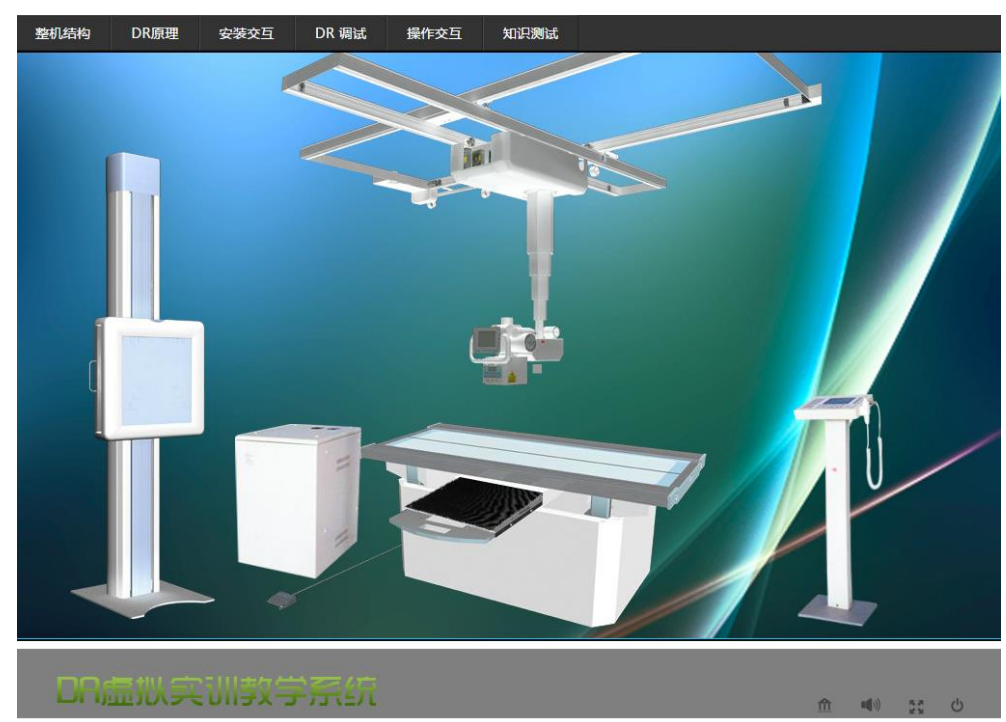

Fig. 2. A DR virtual practice teaching system.

\subsubsection{Other commonly used software}

Medical imaging simulation laboratory also of some commonly used graphics and data processing software installed, as quickly and efficiently deal with data provides a convenient.

\section{Practice of medical imaging simulation laboratory}

\subsection{Teaching function}

Medical imaging simulation laboratory construction for more than a year, for Medical imaging integrated electronics, Microcomputer principle and C program design, Engineering mathematics and medical imaging processing, Micro control unit principle and application, Electronic circuit design and implementation of course provides practical teaching conditions, to carry out the relevant professional practice and computer operation. At the same time, comprehensive practice for electronics, medical image processing, calculation and computer aided innovation training topic research training, practice and graduation design teaching practice to provide enough technical support. Laboratory of the existing teaching function as shown in Table 1. 
Table 1. Teaching function of medical imaging simulation laboratory

\begin{tabular}{|c|c|c|}
\hline Course & Content & Major \\
\hline $\begin{array}{c}\text { Medical imaging } \\
\text { integrated electronics }\end{array}$ & Simulation practice & \multirow{3}{*}{ Medical imaging technology } \\
\hline $\begin{array}{l}\text { Microcomputer principle and } \\
\text { C program design }\end{array}$ & Simulation practice & \\
\hline $\begin{array}{l}\text { Engineering mathematics and } \\
\text { medical imaging processing }\end{array}$ & Simulation practice & \\
\hline $\begin{array}{l}\text { Micro controller unit } \\
\text { principle and application }\end{array}$ & Computer operation & \multirow{3}{*}{$\begin{array}{l}\text { Radiation therapy technology } \\
\text { Medical imaging engineering }\end{array}$} \\
\hline $\begin{array}{c}\text { Electronic circuit } \\
\text { design and implementation }\end{array}$ & Computer operation & \\
\hline $\begin{array}{c}\text { Scientific research training, } \\
\text { practice innovation training, } \\
\text { Course design, graduation design }\end{array}$ & $\begin{array}{l}\text { modeling and } \\
\text { calculation }\end{array}$ & \\
\hline
\end{tabular}

\subsection{Scientific research and technical services}

Medical imaging simulation laboratory provide numerical computing services platform for teachers and scientific research, to solve in the field of medicine, health, engineering and management, and other related technical problems. Through the cooperation with enterprises, universities and research institutes, for medical imaging skills competition of research and application of simulation technology and test. At the same time, can also for the students and related enterprise vocational skills training for medical imaging equipment, etc.

\section{Summary}

To cultivate the students' project practice ability and innovation ability of science and technology must be established to adapt to practical teaching system, strengthen the management modernization and scientific laboratory. Medical imaging simulation laboratory in high quality hardware construction, on the basis of integrated more than medical image related application extensive numerical modeling and simulation software, in our teaching, scientific research and subject construction has played an important role, also provide certain reference for the laboratory construction industry.

\section{Acknowledgement}

This research was financially supported by the Seed Science Foundation of Shanghai University of Medicine and Health Sciences (Grant NO. SFP-18-22-06-002).

\section{References}

[1] L. Wonil, S. Edmund, and L. Ken-Yu, An evaluation of wearable sensors and their placements for analyzing construction worker's trunk posture in laboratory conditions, Applied Ergonomics, vol. 65, pp. 424-436, 2017.

[2] W. Xiong, F. Liao and G. Wei, Design and Practice of New Mode for Experimental Teaching Reform in Pharmaceutical Analysis, China Educational Technology \& Equipment, vol. 133, pp. 244-247, 2013.

[3] A. H. Andrew, E. T. Hakan and P. K. Jens, On-chip quantum simulation with superconducting circuits, Nature Physics, vol. 8, pp. 292-299, 2012.

[4] S. Erick, A. David and J. P. Daniel, Development of a Real-Time Software-Defined GPS Receiver in a LabVIEW-Based Instrumentation Environment, IEEE Transactions on Instrumentation and Measurement, vol. 67, pp. 2082-2096, 2018. 
[5] R. Guizhou, MATLAB/Simulink-Based Simulation and Experimental Validation of a Novel Energy Storage System to a New Type of Linear Engine for Alternative Energy Vehicle Applications, IEEE Transactions on Power Electronics, vol.33, pp. 8683-8694, 2018.

[6] B. Xin, Discussion on the Integration Method of Information Based Teaching for the Mechanical Basic of Medical Imaging Equipment Course, 2017 International Conference on Modern Education and Information Technology, pp. 313-316, 2017. 